\title{
The relationships between petroleum and stock returns: An asymmetric dynamic equi-correlation approach ${ }^{\text {th }}$
}

\author{
Zhiyuan Pan ${ }^{\mathrm{a}, \mathrm{b}}$, Yudong Wang ${ }^{\mathrm{c}, *}, \mathrm{Li} \mathrm{Liu}^{\mathrm{d}}$ \\ ${ }^{a}$ Institute of Chinese Financial Studies, Southwestern University of Finance and Economics, China \\ ${ }^{b}$ Collaborative Innovation Center of Financial Security, China \\ ${ }^{c}$ School of Economics and Management, Nanjing University of Science and Technology \\ ${ }^{d}$ School of Finance, Nanjing Audit University
}

\begin{abstract}
In this paper, we propose an asymmetric dynamic equi-correlation (ADECO) model to investigate the correlations between returns of petroleum futures and stock indices. Our ADECO reveals the in-sample significant asymmetric effect in oil-stock correlations. To evaluate outof-sample performance, we consider a portfolio with petroleum futures and stocks in which the weights are determined by forecasts of covariance matrix. We find that ADECO provides portfolios with better performances than existing popular DECO, DCC and ADCC models in the minimum-variance framework. Moreover, energy price risk can be better hedged by stocks in oil-exporting countries than stocks in oil-importing countries. Our findings are further demonstrated to be robust to the change of futures maturity.
\end{abstract}

Keywords: Asymmetry, Equi-correlation, Petroleum futures, Stock market, Portfolio

\section{Introduction}

Crude oil is the major input of world oil industry. Oil price shocks are expected to have essential impacts on the real economy in both oil-importing and oil-exporting countries. Therefore, it is not surprising that a great number of studies investigate the effects of

\footnotetext{
This work was supported by the Chinese National Science Foundation through grant number 71401077, 71501095, and the Fundamental Research Funds for the Central Universities through grant number 112010004005080004.

*Corresponding author. Tel: +86-13681663442. Address: Xiaolinwei 200, Xuanwu District, Nanjing 210094, China

Email address: wangyudongnj@126.com (Yudong Wang)
} 
oil price shocks on the macroeconomic variables including output and inflation (Hamilton, 1983, 1996, 2003; Mork, 1989; Hooker, 1996; Bernanke et al., 1997; Kilian, 2009), trading account (Schubert, 2014; Kilian et al., 2009), interest rate (Herrera and Pesavento, 2009; Kormilitsina, 2011; Rahman and Serletis, 2010) and stock prices (Kilian and Park, 2009; Park and Ratti, 2008; Wang et al., 2013; Sadorsky, 1999; Papapetrou, 2001). In this paper, we focus on the relationships between crude oil and stock prices.

The rationale behind oil-stock relationship is that innovations in oil prices can cause changes in both real cash flow and expected returns of stocks (Jones and Kaul, 1996). Recently, a strand of studies focuses on the dynamic correlations between oil and stock returns (see, e.g., Arouri et al., 2011; Chang et al., 2013; Creti et al., 2013; Chkili et al., 2014; Filis et al., 2011; Sadorsky, 2012; Wang and Liu, 2015) because correlation (or covariance) has important implications for asset allocation and portfolio optimization. Notably, some studies find the asymmetry in the oil-stock return relationships (see, e.g., Chang et al., 2013; Arouri et al., 2011). Specifically, correlations during the period when stock and oil prices increase are different from those during the period when both prices decrease. This asymmetry can be explained by the asymmetric effects of oil price changes on the real economy (see, e.g., Hamilton, 1996, 2003; Mork, 1989).

In related studies, multivariate GARCH (MVGARCH) models are always employed to reveal the correlated behavior. Although MVGARCH can well capture dynamics of conditional variance and covariance, there are still some limitations in empirical applications. For example, the BEKK-GARCH of Engle and Kroner (1995) is subject to the problem of "limited dimensions". Specifically, it is computationally infeasible to estimate a full BEKK with more than half a dozen variables. Too many parameters to be estimated will interact in a way that is too intricate for existing optimization algorithms to converge in the process of parameter estimation (see, e.g., Ledoit et al., 2003). The dynamic conditional correlation GARCH (DCC-GARCH) of Engle (2002) greatly simplifies multivariate specifications and can be estimated more easily. However, Engle and Sheppard (2005) argue that DCC has only been successfully applied to up to 100 assets and the estimation becomes increasingly cumbersome as the dimension grows. The factor GARCH of Engle et al. (1990) and Ng 
et al. (1992) can deal with large numbers of variables but it suffers from two drawbacks (Engle and Kelly, 2012). First, it is not clear what the factors are or factor data may be not available in the real world. Second, the residuals may be still correlated after controlling for the factors (see, e.g., Engle, 2009a,b; Rangel and Engle, 2012).

To address the drawbacks of traditional MVGARCH in doing with high dimension assets, Engle and Kelly (2012) propose a model called Dynamic Equicorrelation (DECO) which can eliminate the computational and presentational difficulties of high dimension systems. DECO assumes that each pairs of returns in a system display the same correlation which changes over time. Although this assumption looks like a bit strict, likelihood calculation of DECO is greatly simplified and parameter estimation becomes much more feasible for high dimension systems because equicorrelation matrices have simple analytic inverse and determinants.

In this paper, we use DECO to investigate correlations between returns of energy futures and 23 stock market indices in major oil-importing and oil-exporting countries. To accommodate the asymmetry in oil-stock relationships, we extend Engle and Kelly (2012)'s DECO by introducing an asymmetric variable to the dynamic equation of covariance. Our asymmetric DECO (ADECO) considers two asset blocks that the first block contains energy futures and the second block contains stock indices. Following the core assumption of DECO, we also assume that each pair of assets within a block presents the same correlation and the returns of two different assets in various blocks are also correlated in the same way but the correlations are allowed for changing over time.

In addition to aforementioned methodological contribution, we further empirically contribute to the literature in two dimensions. First, we investigate whether oil-stock correlations differ depending on a country's net position in world oil market. A few studies have found that the impacts of oil price shocks on stock market activities rely on whether a country is a net oil exporter or importer (see, e.g., Park and Ratti, 2008; Wang et al., 2013). Therefore, it is highly possible that oil-stock return correlations for oil-importing countries are different from those for oil-exporting countries. However, this issue has been addressed in very few of papers except Filis et al. (2011) and Wang and Liu (2015). Second, to evaluate 
the usefulness of correlation out-of-sample, we consider a portfolio with petroleum futures and stocks in which the optimal weights of individual assets are determined by the forecasts of variance and covariance in the minimum-variance framework. In recent years, commodity futures have emerged as a popular equity-like asset class for many financial institutions due to the financialization of commodity markets (Gorton et al., 2013; Gorton and Rouwenhorst, 2006; Tang and Xiong, 2012). However, how to allocate assets between commodity futures and stocks has not been considered in existing studies. We will fill this gap in this paper.

We employ weekly price data covering the period from 2000 to 2015. Our in-sample evidence suggests that the correlations between oil and stock returns are significantly asymmetric for both oil-importing and oil-exporting countries. The correlations are positive most of time. The plausible explanation is that the major determinant of oil price changes in our sample period is global demand that can drive both oil and stock prices to change in the same direction (Wang and Liu, 2015). The oil-stock correlations are stronger for oilexporting countries than for oil-importing countries. This makes sense because oil-exporting economies depend on crude oil trading more heavily (Wang et al., 2013).

We compare the out-of-sample performances of ADECO with popular DECO, DCC and ADCC models. We find that the optimal portfolio with petroleum futures and stocks in oil-exporting countries display lower return variance than portfolio with petroleum futures and stocks in oil-importing countries. This result holds for each correlation model under consideration, indicating that oil-exporting countries stock market can better hedge oil risk. More importantly, we find that ADECO can provide the portfolios with lower return variance than the other three models, regardless of whether the stocks in oil-exporting or oil-importing countries are used. This finding highlights the importance of accounting for asymmetry in a dynamic correlation model. The reason is that asymmetric model can better capture the phenomenon that oil-stock return correlations during the period when prices increase are significantly different from correlations during the period when prices decrease. For robustness check, we also consider petroleum futures contracts with different maturities. Generally speaking, our out-of-sample results consistently support the superiority of ADECO in modeling and forecasting the correlations between petroleum and stock returns. 
The remainder of this paper is organized as follows: Section 2 presents the model specification and estimation method of ADECO. Section 3 provides data and some preliminary analysis. Section 4 shows the main empirical results. The last section concludes the paper.

\section{Methodology}

We extend the dynamic equicorrelation (DECO) model by introducing the asymmetry to the dynamic process of conditional covariance. Then, we use the proposed asymmetric DECO (ADECO) model to investigate the relationships between the two groups of stock index and petroleum futures returns. In this section, we show the specification and the methodology of parameter estimation of ADECO.

Suppose the vector of asset returns is denoted by $r_{t}=\left(r_{1, t}, r_{2, t}, \cdots, r_{n, t}\right)^{\prime}$, where $r_{i, t}$ is the return of the $i$ th asset at time $t$ and $n$ is the total number of financial assets, our model is given by,

$$
\begin{aligned}
r_{t} & =\bar{\mu}+\phi \odot r_{t-1}+e_{t} \\
& =\bar{\mu}+\phi \odot r_{r-1}+H_{t}^{1 / 2} z_{t}
\end{aligned}
$$

where $\bar{\mu}=\left(\bar{\mu}_{1}, \cdots, \bar{\mu}_{n}\right)^{\prime}$ is the constant conditional mean vector and coefficient $\phi=\left(\phi_{1}, \cdots, \phi_{n}\right)^{\prime}$. The symbol $\odot$ means element-by-element multiplication. $H_{t}$ is the variance-covariance matrix of returns and $H_{t}^{1 / 2}$ can be obtained by the Cholesky decomposition of $H_{t}$. $z_{t}$ follows the standard multivariate normal distribution.

Following the DCC model of Engle $(2002), H_{t}$ can be decomposed as follows:

$$
H_{t}=D_{t} R_{t} D_{t}
$$

where $D_{t}=\operatorname{diag}\left(\sqrt{h_{1 t}}, \cdots, \sqrt{h_{n t}}\right)$ is a diagonal matrix in which the diagonal elements $h_{k t}, k=1, \cdots, n$, follow the process of a univariate GARCH process. $R_{t}$ is a conditional correlation matrix. Therefore, let $\tilde{r}_{t}=D_{t}^{-1}\left(r_{t}-\bar{\mu}-\phi \odot r_{t-1}\right)$, we have

$$
\tilde{r}_{t} \mid \mathcal{F}_{t-1} \sim \mathcal{N}\left(0, R_{t}\right)
$$


where $\mathcal{F}_{t-1}$ denotes the information available at time $t$. The dynamic process of correlation matrix can be written as follows:

$$
\begin{gathered}
Q_{t}=\bar{Q}(1-a-b)-\bar{K} g+a \tilde{r}_{t-1} \tilde{r}_{t-1}^{\prime}+g k_{t-1} k_{t-1}^{\prime}+b Q_{t-1} \\
R_{t}=Q_{t}^{*-1} Q_{t} Q_{t}^{*-1}
\end{gathered}
$$

where $\bar{Q}=E\left[\tilde{r}_{t} \tilde{r}_{t}^{\prime}\right], k_{t}=I\left(\tilde{r}_{t}<0\right) \odot \tilde{r}_{t}, \bar{K}=E\left[k_{t} k_{t}^{\prime}\right]$. Since the expectations for $\bar{Q}$ and $\bar{K}$ are unavailable in practice, we replace them with their sample analogues, $T^{-1} \sum_{t=1}^{T} \tilde{r}_{t} \tilde{r}_{t}^{\prime}$ and $T^{-1} \sum_{t=1}^{T} k_{t} k_{t}^{\prime}$, respectively. $T$ is the sample size. $I(\cdot)$ is an indicator function which takes the value of 1 when the condition in the parenthesis is satisfied and zero otherwise. $Q_{t}^{*}=\operatorname{diag}\left(\sqrt{q_{11 t}}, \cdots, \sqrt{q_{n n t}}\right)$ is a diagonal matrix, in which the elements are the square root of corresponding elements in $Q_{t}$.

From Equation (4), we can see that the parameter $g$ describes the role of asymmetric effect. The positive value of $g$ implies that the correlations are stronger during the period when asset prices decrease than the correlations during the period when asset prices increase. This asymmetry has been a stylized fact in stock markets (see, e.g., Longin and Solnik, 2001; Ang and Chen, 2002). Apparently, DECO can be taken as a special case of ADECO for $g=0$. To ensure that $Q_{t}$ is a positive-definite matrix, the sufficient and necessary conditions are needed as follows (Cappiello et al., 2006):

$$
a, b, g>0 ; \quad a+b+\lambda_{\max } g<1,
$$

where $\lambda_{\max }$ is the maximum eigenvalue of the matrix $\bar{Q}^{-1 / 2} \bar{K} \bar{Q}^{-1 / 2}$.

It is argued that the DCC specification of equations (4) and (5) becomes much more difficult to estimate when the number of assets increases. The main reason is that the inverse and determinant of matrix $R_{t}$ cannot be expressed explicitly. Too high dimension of asset return matrix is likely to cause the unavailability of likelihood function of equation (3) due to the out-of-memory of computer system. To overcome this problem, we follow Engle and Kelly (2012) by imposing following two assumptions on the structure of conditional correlation matrix. We consider a two-block case of Engle and Kelly (2012)'s DECO model, in which the first block contains energy futures and the second block contains stock indices. 
The first basic assumption is that returns of each pair of assets within a block display the same correlation at a given time. The second assumption is that returns of each two assets belonging to two different blocks also present the same correlation. Certainly, all correlations are allowed to change over time. According to these two assumptions,

$$
R_{t}=\left[\begin{array}{cc}
\left(1-\rho_{11, t}\right) I_{n_{1}} & 0 \\
0 & \left(1-\rho_{22, t}\right) I_{n_{2}}
\end{array}\right]+\left[\begin{array}{cc}
\rho_{11, t} J_{n_{1} \times n_{1}} & \rho_{12, t} J_{n_{1} \times n_{2}} \\
\rho_{21, t} J_{n_{2} \times n_{1}} & \rho_{22, t} J_{n_{2} \times n_{2}}
\end{array}\right],
$$

where $I_{p}$ is the $p$-dimensional identity matrices, and $J_{p_{1} \times p_{2}}$ denotes the $p_{1} \times p_{2}$ matrices of ones, and at $t$ time, we have,

$$
\begin{gathered}
\rho_{k k, t}=\frac{1}{n_{k}\left(n_{k}-1\right)} \sum_{i \in k, j \in k, i \neq j} \frac{q_{i j, t}}{\sqrt{q_{i i, t} q_{j j, t}}}, \quad k=1,2 ; \\
\rho_{k_{1} k_{2}, t}=\rho_{k_{2} k_{1}, t}=\frac{1}{n_{k_{1}} n_{k_{2}}} \sum_{i \in k_{1}, j \in k_{2}} \frac{q_{i j, t}}{\sqrt{q_{i i, t} q_{j j, t}}}, \quad k_{1}, k_{2}=1,2 \text { and } k_{1} \neq k_{2} .
\end{gathered}
$$

where the number 1 and 2 denote Block 1 and 2, respectively. $q_{i j, t}$ is the element in the matrix $Q_{t}$.

As $R_{t}$ is the covariance of $\tilde{r}_{t}$ (see, equation(3)), thus we need to impose some restrictions to guarantee that this covariance matrix is positive semi-definite. Following Engle and Kelly (2012), we give the positive definite condition for matrix $R_{t}$ as

$$
\rho_{i} \in\left(\frac{-1}{n_{i}-1}, 1\right), \quad i=1,2
$$

and

$$
\rho_{1,2} \in\left(-\sqrt{\frac{\left(\rho_{1,1}\left(n_{1}-1\right)+1\right)\left(\rho_{2,2}\left(n_{2}-1\right)+1\right)}{n_{1} n_{2}}}, \sqrt{\left.\frac{\left(\rho_{1,1}\left(n_{1}-1\right)+1\right)\left(\rho_{2,2}\left(n_{2}-1\right)+1\right)}{n_{1} n_{2}}\right)}\right.
$$

The two restrict conditions above are equivalent to the requirement that all eigenvalues of matrix $R_{t}$ are positive, which leads to matrix $R_{t}$ being positive definite.

According to Lemma 2.3 in Engle and Kelly (2012) paper, the inverse and determinant of correlation matrix can be explicitly written as,

$$
R_{t}^{-1}=\left[\begin{array}{cc}
b_{1, t} I_{n_{1}} & 0 \\
0 & b_{2, t} I_{n_{2}}
\end{array}\right]+\left[\begin{array}{cc}
c_{1, t} J_{n_{1} \times n_{1}} & c_{3, t} J_{n_{1} \times n_{2}} \\
c_{3, t} J_{n_{2} \times n_{1}} & c_{2, t} J_{n_{2} \times n_{2}}
\end{array}\right]
$$


where

$$
\begin{gathered}
b_{i, t}=\frac{1}{1-\rho_{i i, t}}, \quad i=1,2, \\
c_{1, t}=\frac{\rho_{11, t}\left[\rho_{22, t}\left(n_{2}-1\right)+1\right]-\rho_{12, t}^{2} n_{2}}{\left(\rho_{11, t}-1\right)\left\{\left[\rho_{11, t}\left(n_{1}-1\right)+1\right]\left[\rho_{22, t}\left(n_{2}-1\right)+1\right]-n_{1} n_{2} \rho_{12, t}^{2}\right\}}, \\
c_{2, t}=\frac{\rho_{22, t}\left[\rho_{11, t}\left(n_{1}-1\right)+1\right]-\rho_{12, t}^{2} n_{1}}{\left(\rho_{22, t}-1\right)\left\{\left[\rho_{11, t}\left(n_{1}-1\right)+1\right]\left[\rho_{22, t}\left(n_{2}-1\right)+1\right]-n_{1} n_{2} \rho_{12, t}^{2}\right\}}, \\
c_{3, t}=\frac{\rho_{12, t}}{n_{1} n_{2} \rho_{12, t}^{2}-\left[\rho_{11, t}\left(n_{1}-1\right)+1\right]\left[\rho_{22, t}\left(n_{2}-1\right)+1\right]} .
\end{gathered}
$$

and

$$
\left|R_{t}\right|=\left(1-\rho_{11, t}\right)^{n_{1}-1}\left(1-\rho_{22, t}\right)^{n_{2}-1}\left\{\left[1+\left(n_{1}-1\right) \rho_{11, t}\right]\left[1+\left(n_{2}-1\right) \rho_{22, t}\right]-\rho_{12, t}^{2} n_{1} n_{2}\right\}
$$

The log likelihood function based on $R_{t}^{-1}$ and $\left|R_{t}\right|$ is given by,

$$
\text { Loglik }=-\frac{1}{2} \sum_{t=1}^{T}\left(\log \left|R_{t}\right|+\tilde{r}_{t}^{\prime} R_{t}^{-1} \tilde{r}_{t}\right) .
$$

We can see that for any asset number, the log likelihood is simplified greatly. We can calculate the sum of this log likelihood for both blocks and estimate the model parameters via maximizing this $\operatorname{sum}^{1}$.

Following Engle and Kelly (2012), we use the two-step method to estimate the parameters of our ADECO. At the first step, we estimate the parameters of univariate GARCH model for returns of individual assets in each block. Then, we estimate the dynamic equation ADECO (equation (4)). We employ the $\operatorname{AR}(1)-G J R(1,1)$ specification $^{2}$ to model the dynamics of return volatility of individual assets:

$$
\begin{aligned}
r_{i, t} & =\mu+\phi r_{i, t-1}+\sqrt{h_{i, t}} \epsilon_{i, t} \\
h_{i, t} & =\bar{\omega}+\alpha e_{i, t-1}^{2}+\gamma I\left[e_{i, t-1}<0\right] e_{i, t-1}^{2}+\beta h_{i, t-1} \\
\epsilon_{i, t} & \sim \mathcal{N}(0,1)
\end{aligned}
$$

\footnotetext{
${ }^{1}$ This method is called composite likelihood, which is always used to estimate high-dimension models. For the detailed description of this method, one can refer to the literature review in Varin et al. (2011).

${ }^{2}$ Since it is found in the literature that stock returns are significantly autocorrelated (see, e.g., Di Matteo et al., 2005), we use AR(1) to capture dynamics of conditional mean. Glosten et al. (1993) further find that the stock volatility is always greater when stock price decreases than when stock price increases. To account for this asymmetry, we use GJR model to describe conditional volatility of stock and oil returns.
} 
where $i=1, \cdots, n$.

\section{Data}

We employ weekly futures price data of three energy commodities including crude oil, gasoline and heating oil. All these energy futures contracts are traded in NYMEX. For each commodity, we consider futures contracts with four different maturities. Contract 1 denotes the one specifying the earliest delivery date. For gasoline and heating oil each contract expires on the last business day of the month preceding the delivery month. Thus, the delivery month for Contract 1 is the calendar month following the trade date. For crude oil, each contract expires on the third business day prior to the 25th calendar day of the month preceding the delivery month. If the 25 th calendar day of the month is a non-business day, trading ceases on the third business day prior to the business day preceding the 25th calendar day. After a contract expires, Contract 1 for the remainder of that calendar month is the second following month. Contract 2-4 represents the successive delivery months following Contract 1. All energy price data are collected from the website of Energy Information Administration (EIA) (www.eia.gov). The graphical illustrations of energy futures prices are given in Figure 1.

\section{Insert Figure 1 here}

We choose weekly stock indices in 11 major oil-exporting countries and 12 oil-importing countries. We use the weekly data even though daily data are available because it is less possible to rebalance portfolios every day due to the effect of transaction cost. High-frequency data also brings greater computational burden in the process of obtaining out-of-sample forecasts. Our selection criteria for these countries are based on Kilian et al. (2009) and Wang et al. (2013). Generally speaking, we choose the countries with the highest oil export (or import) volume. But we exclude several major exporters such as Iran and Iraq since the stock price data are not available or very limited for these countries (Jung and Park, 2011). All stock indices are transformed to US dollar prices to eliminate the effect of exchange rates. The stock indices and exchange rates data are obtained from Bloomberg database. Table 1 
lists the name of stock indices and corresponding country names. We plot the stock prices in oil-exporting countries and oil-importing countries in Figures 2 and 3, respectively. Our data cover the period from February 2000 to August 2015. Our sample starts from January 2000 because for the stock indices of some countries such as Saudi Arabia are unavailable earlier than this time point.

\section{Insert Table 1 and Figures 2-3 here}

In the empirical analysis, we use the stock returns which are obtained by calculating the log differences of prices. In order to compare the performances between commodity and stocks meaningfully, we follow the literature by controlling the leverage in futures trading. Specifically, we assume that futures positions are fully collateralized (see, e.g., Hong and Yogo, 2012; De Roon et al., 2000; Gorton et al., 2013). When an investor buys contract with a futures price of 50 dollars, he or she should simultaneously invest 50 dollars in Treasury bills. The total return earned by the investor over a given period is the change in futures price and the interest rate on the 50 dollars, scaled by the initial 50 dollars investment. In this way, the energy futures returns can be calculated as follows:

$$
r_{e, t}=\log \left(F_{e, t}\right)-\log \left(F_{e, t-1}\right)+r_{f, t}
$$

where $F_{e, t}$ is the futures price at week $t$ and $r_{f, t}$ is the risk-free rate.

Table 2 reports the descriptive statistics of energy and stock returns. We can find that all energy returns as well as stock returns display the positive mean values but negative skewnesses. The standard deviations suggest that energy prices are more volatile than most stock prices. The Jarque-Bera statistics show rejections of the null hypothesis of Gaussian distribution for all return series, indicating the fat-tail distribution. The Ljung-Box statistics show the rejection of the null hypothesis of no serial correlation up to the order of 10 . This motivates us to use the $\mathrm{AR}(1)$ model to capture the conditional mean of returns. The chi-square statistics of ARCH test also reject the null hypothesis of no ARCH effect, which motivates us to employ GARCH specification to capture the dynamics of conditional variance of individual assets. 


\section{Insert Table 2 here}

\section{Empirical results}

In this section, we first show the in-sample estimation results of our ADECO to see whether the asymmetry exists in energy-stock return relationships. Second, we give the out-of-sample performance of ADECO in portfolio allocation. Finally, we perform some robustness checks on the performance of ADECO.

\subsection{Are the relationships between energy and stock returns asymmetric?}

We consider the two-block ADECO in which the first block contains nearby contracts of three energy futures and the second block contains stock indices. Table 3 reports the estimation results of ADECO for energy futures and stocks in oil-importing countries, as well as results for oil-exporting countries. We can find that the parameter $b$ in each caseis greater than 0.9 and highly significant, suggesting the persistence in correlations between energy and stock returns. The asymmetry parameter $g$ is also significant at $10 \%$ level in each case, indicating that the energy-stock correlations are asymmetric for both oilimporting and oil-exporting countries. In our sample period, global oil demand replaces supply as the main determinant of oil price changes. For example, it is well documented in the literature that the oil price increases from 2003 to mid-2008 are driven by high oil demand in emerging economies such as China and India (Hamilton, 2009; Kilian, 2009). The global economic depression triggered by financial crisis in mid-2008-2009 is also considered as a typical demand shock which resulted in a large crash in oil prices. It is intuitive that the expansion of the economy can stimulate both crude oil and stock prices. For oilimporting countries, increases in oil prices can also lead to higher industry cost and import cost, which will have negative impacts on stock markets. These negative impacts can largely offset the initial positive impacts of economic growth on stock markets with time goes by (Kilian and Park, 2009; Wang et al., 2013). Differently, the depression in global oil economic activities leads to both decreases in oil and stock prices. However, the marginal effect of oil price decrease on economies is not as large as the marginal effect of oil price increase in 
magnitude (see, e.g., Mork, 1989; Hamilton, 1996) and therefore cannot offset the negative impacts of economic depression. In this sense, the asymmetric relationships between returns of crude oil and stocks are observed.

\section{Insert Table 3 here}

Figure 4 and 5 show the conditional correlations calculated from ADECO for returns of oil and oil-importing country stocks and for returns of oil and oil-exporting country stocks, respectively. It is intuitive that correlations within energy futures block are much higher than correlations within the stocks block. The reason is that gasoline and heating oil are the refined products of crude oil. Price changes of these three energy commodities share a large component that is affected by the same supply and demand shocks. We can also find that the correlations of stock returns in oil-importing countries are always higher than those in oil-exporting countries. The plausible explanation is that some geopolitical events (such as the second Gulf War, "Arab Spring" and Venezuela Strikes) occur in oil-exporting countries more frequently, leading to structural breaks in stock prices and therefore lower comovement of stock returns. Furthermore, the correlations between energy and stock in both oil-importing and oil-exporting countries are positive most of time. This is because the global economic activity drives oil and stock prices to change in the same direction. Oil-stock correlations for oil-exporting countries are stronger than for oil-importing countries most of time. The plausible explanation is that these oil-exporting economies depend on oil trading more heavily and oil price shocks thereby have greater effects on their stock markets (Wang et al., 2013).

\section{Insert Figure 4 and Figure 5 here}

\subsection{Portfolio exercise}

We have used ADECO to reveal the asymmetry in the energy-stock relationships from insample analysis. In comparison with in-sample performance, market participants are more concerned about out-of-sample performance because they would like to know how well they can do by using this model in the future. To find the role of asymmetry out-of-sample, we 
compare the performance of ADECO with three alternative strategies which are Engle and Kelly (2012)'s DECO, Engle (2002)'s DCC amd Cappiello et al. (2006)'s ADCC models. These three strategies have been widely applied in empirical studies.

To evaluate the out-of-sample performance in an economically meaningful way, we follow Engle and Kelly (2012)'s methodology by using out-of-sample covariance forecasts to form minimum variance portfolios. A superior forecasting model should provide portfolios that display lower variances than portfolios formed based on competing models. Consider a collection of $n$ assets with covariance matrix , the minimum-variance (MV) portfolio weights are the solution to the problem,

$$
\min _{\omega_{t}} \omega_{t}^{\prime} H_{t} \omega_{t} \quad \text { s.t. }, \quad \omega_{t}^{\prime} \iota_{n}=1
$$

The optimal weights can be written as,

$$
\omega_{t}=\frac{H_{t}^{-1} \iota_{n}}{\iota_{n}^{\prime} H_{t}^{-1} \iota_{n}}
$$

More strictly, the Equations (21) and (22) provide solutions for optimal weights for a global minimum-variance (GMV) portfolio. The minimum variance (MV) portfolio is subject to one additional constraint, involving unknown expected returns. That is,

$$
\omega^{\prime} \nu \geq q
$$

where $\omega$ and $\nu$ denote vectors of weight and the expected return, respectively; $q$ is prespecified at least achievement level of expected return.

Unfortunately, Merton (1980) pointed out that it is difficult to estimate expected returns than covariance matrix from historical data, and the errors from estimates of expected returns have a larger impact on portfolio weights than that from estimates of covariance matrix. To avoid the impact of expected returns, recent most papers have adopted global minimum-variance (GMV) to investigate their performance of portfolio (DeMiguel et al., 2009; Jin and Maheu, 2012), so do we in this paper.

Our forecast experiment is executed as follows. We use the weekly returns of stock and energy returns for the estimation window of $M$ weeks $(M=400$ in our case, i.e., about 8 
years). First, we use the returns for the first $M$ weeks to estimate the parameters of univariate volatility models (i.e., GJR model). Second, we use parameter estimates of univariate volatility models to construct one-step-ahead volatility forecasts for each of stock and energy returns.Third, we use the standardized residuals from the first step to estimate the dynamic correlation model. Forth, we use the parameter estimates for the dynamic correlation model to form correlation forecasts. According to the basic assumption of DECO, the correlation between two asset returns within the same block is the same and the correlation between two asset returns in two different blocks is also the same at one specific time point but changes over time. We thereby need 3 correlation forecasts for two-block ADECO at each time point. Fifth, we combine correlation forecasts and volatility forecasts to construct the forecasts of full covariance matrix in Week $M+1$. In the same way, we employ the observations from Week 2 to Week $M+1$ to obtain covariance forecast in Week $M+2$. This procedure is repeated until data through August 26, 2015, resulting in $T-M$ forecasts of covariance matrix. The covariance forecasts are used to determine the ex-ante optimal weights via Equation (22) and the realized returns of optimal portfolio are then available accordingly.

We consider two portfolios with different assets and the weights of individual assets in each portfolio are determined by covariance forecasts. The first portfolio contains stock indices only (Portfolio I) and the second portfolio contains both energy futures and stocks (Portfolio II). The performances of these two portfolios formed by different models are reported in Table 4. We use the Diebold and Mariano (1995) test to examine whether the differences of two portfolio variances are statistically significant. For each given model, the portfolio II presents lower variance than portfolio I, regardless of whether oil-importing or oil-exporting countries' stocks are used. This result indicates that adding energy futures to stock portfolio can reduce its variance. The optimal portfolio for energy futures and stocks in oil-exporting countries has lower variance than the portfolio for energy futures and stocks in oil-importing countries. Such finding implies that oil-exporting countries stock market can better hedge energy risk. ADECO model results in the portfolio with significantly lower variance than each of the other three models, suggesting the best out-of-sample hedging 
performance. Moreover, ADECO and ADCC can provide portfolios with lower variance than portfolios formed based on DECO and DCC models, respectively. Moreover, the DM test results show that the differences between out-of-sample performances of ADECO (ADCC) and its symmetric counterpart are significant at $10 \%$ level in most cases. This result suggests that considering asymmetric oil-stock relationships can improve the performance of hedged portfolio.

\section{Insert Table 4 here}

Our main empirical analysis is performed based on nearby futures contracts. For robustness, we also consider the other three futures contracts. We show the performances of portfolios formed by ADECO, DECO, ADCC and DCC in Table 5 when these alternative futures contracts are used. We can find that the effects of futures maturity on portfolio performances are minor. More importantly, our two findings that stocks in oil-exporting countries can better hedge energy price risk and that ADECO performs better than the other three models out-of-sample still hold consistently. Therefore, we can conclude that our main empirical results are robust to the changes of futures maturity.

\section{Insert Table 5 here}

\section{Conclusions}

In this paper, we extend Engle and Kelly (2012) DECO model by introducing an asymmetric variable. The proposed asymmetric DECO (ADECO) model is used to investigate the relationships between petroleum and stock returns, the issue which is of great interest for academics in recent years. We employ futures contracts of crude oil and its refined products (e.g., gasoline and heating oil) and stock indices in 11 oil-exporting countries and 12 oil-importing countries. We find the significant asymmetric effect in oil-stock relationships. Their correlations are positive most of time and are stronger for oil-exporting countries than for oil-importing countries. To evaluate the out-of-sample performance of ADECO, we consider a portfolio with energy futures and stock indices in which the optimal weights 
are determined by forecasts of covariance matrix in the minimum-variance framework. We find that ADECO can provide portfolios with lower variance than DECO and DCC models. Moreover, stock indices in oil-exporting countries can better hedge oil price risk than stock indices in oil-importing countries.

\section{References}

Ang, A., Chen, J., 2002. Asymmetric correlations of equity portfolios. Journal of Financial Economics 63 (3), 443-494.

Arouri, M. E. H., Jouini, J., Nguyen, D. K., 2011. Volatility spillovers between oil prices and stock sector returns: implications for portfolio management. Journal of International money and finance 30 (7), 13871405.

Bernanke, B. S., Gertler, M., Watson, M., Sims, C. A., Friedman, B. M., 1997. Systematic monetary policy and the effects of oil price shocks. Brookings papers on economic activity, 91-157.

Cappiello, L., Engle, R. F., Sheppard, K., 2006. Asymmetric dynamics in the correlations of global equity and bond returns. Journal of Financial econometrics 4 (4), 537-572.

Chang, C.-L., McAleer, M., Tansuchat, R., 2013. Conditional correlations and volatility spillovers between crude oil and stock index returns. The North American Journal of Economics and Finance 25, 116-138.

Chkili, W., Hammoudeh, S., Nguyen, D. K., 2014. Volatility forecasting and risk management for commodity markets in the presence of asymmetry and long memory. Energy Economics 41, 1-18.

Creti, A., Joëts, M., Mignon, V., 2013. On the links between stock and commodity markets' volatility. Energy Economics 37, 16-28.

De Roon, F. A., Nijman, T. E., Veld, C., 2000. Hedging pressure effects in futures markets. Journal of Finance, $1437-1456$.

DeMiguel, V., Garlappi, L., Nogales, F. J., Uppal, R., 2009. A generalized approach to portfolio optimization: Improving performance by constraining portfolio norms. Management Science 55 (5), 798-812.

Di Matteo, T., Aste, T., Dacorogna, M. M., 2005. Long-term memories of developed and emerging markets: Using the scaling analysis to characterize their stage of development. Journal of Banking \& Finance 29 (4), $827-851$

Diebold, F. X., Mariano, R. S., 1995. Comparing predictive accuracy. Journal of Business \& Economic Statistics 13 (3).

Engle, R., 2002. Dynamic conditional correlation: A simple class of multivariate generalized autoregressive conditional heteroskedasticity models. Journal of Business \& Economic Statistics 20 (3), 339-350. 
Engle, R., Kelly, B., 2012. Dynamic equicorrelation. Journal of Business \& Economic Statistics 30 (2), $212-228$.

Engle, R., Sheppard, K., 2005. Theoretical properties of dynamic conditional correlation multivariate garch. University of California, San Diego Working Paper.

Engle, R. F., 2009a. The risk that risk will change. Journal of investment management 16 (4), 24.

Engle, R. F., 2009b. High dimension dynamic correlations. The Methodology and Practice of Econometrics: A Festschrift in Honour of David F. Hendry: A Festschrift in Honour of David F. Hendry, 122.

Engle, R. F., Kroner, K. F., 1995. Multivariate simultaneous generalized arch. Econometric theory 11 (01), $122-150$.

Engle, R. F., Ng, V. K., Rothschild, M., 1990. Asset pricing with a factor-arch covariance structure: Empirical estimates for treasury bills. Journal of Econometrics 45 (1), 213-237.

Filis, G., Degiannakis, S., Floros, C., 2011. Dynamic correlation between stock market and oil prices: The case of oil-importing and oil-exporting countries. International Review of Financial Analysis 20 (3), 152164.

Glosten, L. R., Jagannathan, R., Runkle, D. E., 1993. On the relation between the expected value and the volatility of the nominal excess return on stocks. The journal of finance 48 (5), 1779-1801.

Gorton, G., Rouwenhorst, K. G., 2006. Facts and fantasies about commodity futures. Financial Analysts Journal $62(2), 47-68$.

Gorton, G. B., Hayashi, F., Rouwenhorst, K. G., 2013. The fundamentals of commodity futures returns. Review of Finance 17 (1), 35-105.

Hamilton, J. D., 1983. Oil and the macroeconomy since world war ii. The Journal of Political Economy, $228-248$.

Hamilton, J. D., 1996. This is what happened to the oil price-macroeconomy relationship. Journal of Monetary Economics 38 (2), 215-220.

Hamilton, J. D., 2003. What is an oil shock? Journal of econometrics 113 (2), 363-398.

Hamilton, J. D., 2009. Causes and consequences of the oil shock of 2007-08. Tech. rep., National Bureau of Economic Research.

Herrera, A. M., Pesavento, E., 2009. Oil price shocks, systematic monetary policy, and the great moderation. Macroeconomic Dynamics 13 (01), 107-137.

Hong, H., Yogo, M., 2012. What does futures market interest tell us about the macroeconomy and asset prices? Journal of Financial Economics 105 (3), 473-490.

Hooker, M. A., 1996. What happened to the oil price-macroeconomy relationship? Journal of monetary Economics 38 (2), 195-213.

Jin, X., Maheu, J. M., 2012. Modeling realized covariances and returns. Journal of Financial Econometrics, 
nbs022.

Jones, C. M., Kaul, G., 1996. Oil and the stock markets. The Journal of Finance 51 (2), 463-491.

Jung, H., Park, C., 2011. Stock market reaction to oil price shocks: a comparison between an oil-exporting economy and an oil-importing economy. Journal of Economic Theory and Econometrics 22 (3).

Kilian, L., 2009. Not all oil price shocks are alike: Disentangling demand and supply shocks in the crude oil market. The American Economic Review, 1053-1069.

Kilian, L., Park, C., 2009. The impact of oil price shocks on the us stock market*. International Economic Review 50 (4), 1267-1287.

Kilian, L., Rebucci, A., Spatafora, N., 2009. Oil shocks and external balances. Journal of International Economics 77 (2), 181-194.

Kormilitsina, A., 2011. Oil price shocks and the optimality of monetary policy. Review of Economic Dynamics $14(1), 199-223$.

Ledoit, O., Santa-Clara, P., Wolf, M., 2003. Flexible multivariate garch modeling with an application to international stock markets. Review of Economics and Statistics 85 (3), 735-747.

Longin, F., Solnik, B., 2001. Extreme correlation of international equity markets. The Journal of Finance $56(2), 649-676$.

Merton, R. C., 1980. On estimating the expected return on the market: An exploratory investigation. Journal of financial economics 8 (4), 323-361.

Mork, K. A., 1989. Oil and the macroeconomy when prices go up and down: an extension of hamilton's results. Journal of political Economy, 740-744.

Ng, V., Engle, R. F., Rothschild, M., 1992. A multi-dynamic-factor model for stock returns. Journal of Econometrics 52 (1), 245-266.

Papapetrou, E., 2001. Oil price shocks, stock market, economic activity and employment in greece. Energy Economics 23 (5), 511-532.

Park, J., Ratti, R. A., 2008. Oil price shocks and stock markets in the us and 13 european countries. Energy Economics 30 (5), 2587-2608.

Rahman, S., Serletis, A., 2010. The asymmetric effects of oil price and monetary policy shocks: A nonlinear var approach. Energy Economics 32 (6), 1460-1466.

Rangel, J. G., Engle, R. F., 2012. The factor-spline-garch model for high and low frequency correlations. Journal of Business \& Economic Statistics 30 (1), 109-124.

Sadorsky, P., 1999. Oil price shocks and stock market activity. Energy Economics 21 (5), 449-469.

Sadorsky, P., 2012. Correlations and volatility spillovers between oil prices and the stock prices of clean energy and technology companies. Energy Economics 34 (1), 248-255.

Schubert, S. F., 2014. Dynamic effects of oil price shocks and their impact on the current account. Macroe- 
conomic Dynamics 18 (02), 316-337.

Tang, K., Xiong, W., 2012. Index investment and the financialization of commodities. Financial Analysts Journal 68 (5), 54-74.

Varin, C., Reid, N., Firth, D., 2011. An overview of composite likelihood methods. Statistica Sinica, 5-42.

Wang, Y., Liu, L., 2015. Crude oil and world stock markets: volatility spillovers, dynamic correlations, and hedging. Empirical Economics, 1-29.

Wang, Y., Wu, C., Yang, L., 2013. Oil price shocks and stock market activities: Evidence from oil-importing and oil-exporting countries. Journal of Comparative Economics 41 (4), 1220-1239. 
Table 1: A list of stock indices.

\begin{tabular}{|c|c|c|c|}
\hline \multicolumn{2}{|c|}{ Oil-exporting countries } & \multicolumn{2}{|c|}{ Oil-importing countries } \\
\hline Stock indices & Countries & Stock indices & Countries \\
\hline DSM index & Qatar & AEX index & Holland \\
\hline FBMKCI index & Indonesia & ASX index & UK \\
\hline IBOV index & Brazil & BELSTK index & Belgium \\
\hline IBVC index & Venezuela & CDAX index & Germany \\
\hline INDEXCF index & Russian & FSSTI index & Singapore \\
\hline MEXBOL index & Mexico & KOSPI index & Korea \\
\hline MSM30 index & Oman & MADX index & Spain \\
\hline NGSEINDX index & Nigeria & NIFTY index & India \\
\hline OSEAX index & Norway & NKY index & Japan \\
\hline SASEIDX INDEX & Saudi Arabia & SBF250 index & French \\
\hline \multirow[t]{2}{*}{ SPTSX index } & Canada & SHCOMP index & China \\
\hline & & SPX index & US \\
\hline
\end{tabular}


Table 2: Descriptive statistics of energy futures and stock returns.

\begin{tabular}{|c|c|c|c|c|c|c|c|}
\hline countries & mean & std & skew & kurtosis & JB stat & LBQ stat & ARCH stat \\
\hline \multicolumn{8}{|c|}{ Energy commodities } \\
\hline Crude oil & 0.188 & 0.758 & -0.236 & 5.144 & $163.062^{* * *}$ & $15.424^{* * *}$ & $57.009^{* * *}$ \\
\hline Gasoline & 0.255 & 0.901 & -0.144 & 5.633 & $237.354^{* * *}$ & $13.463^{* *}$ & $83.335^{* * *}$ \\
\hline Heating oil & 0.271 & 0.728 & -0.133 & 4.126 & $45.273^{* * *}$ & 4.027 & $57.161^{* * *}$ \\
\hline \multicolumn{8}{|c|}{ Stocks indices of oil-exporting countries } \\
\hline Qatar & 0.656 & 0.554 & -1.141 & 13.479 & $3891.293^{* * *}$ & $14.782^{* *}$ & $84.330^{* * *}$ \\
\hline Indonesia & 0.126 & 0.376 & -0.356 & 5.083 & $163.895^{* * *}$ & $10.981^{*}$ & $53.431^{* * *}$ \\
\hline Brazil & 0.091 & 0.834 & -1.324 & 12.796 & $3484.047^{* * *}$ & $30.023^{* * *}$ & $31.440^{* * *}$ \\
\hline Venezuela & 1.768 & 0.830 & -0.818 & 44.613 & $58678.673^{* * *}$ & $31.430^{* * *}$ & 1.431 \\
\hline Russian & 0.421 & 0.869 & -1.011 & 12.861 & $3428.629^{* * *}$ & $19.944^{* * *}$ & $123.256^{* * *}$ \\
\hline Mexico & 0.388 & 0.603 & -1.350 & 15.141 & $5233.534^{* * *}$ & $17.905^{* * *}$ & $60.000^{* * *}$ \\
\hline Oman & 0.285 & 0.429 & -1.369 & 21.775 & $12180.383^{* * *}$ & $27.409^{* * *}$ & $175.028^{* * *}$ \\
\hline Nigeria & 0.274 & 0.571 & -0.011 & 6.571 & $431.424^{* * *}$ & $24.499^{* * *}$ & $64.624^{* * *}$ \\
\hline Norway & 0.376 & 0.636 & -1.006 & 7.897 & $948.438^{* * *}$ & $21.385^{* * *}$ & $224.756^{* * *}$ \\
\hline Saudi Arabia & 0.406 & 0.556 & -1.531 & 11.663 & $2855.962^{* * *}$ & $17.587^{* * *}$ & $112.727^{* * *}$ \\
\hline Canada & 0.161 & 0.490 & -0.827 & 7.072 & $653.517^{* * *}$ & $14.488^{* *}$ & $169.530^{* * *}$ \\
\hline \multicolumn{8}{|c|}{ Stock indices of oil-importing countries } \\
\hline Holland & -0.071 & 0.563 & -0.636 & 6.779 & $537.882^{* * *}$ & $14.133^{* *}$ & $125.725^{* * *}$ \\
\hline UK & 0.019 & 0.448 & -0.610 & 5.993 & $353.611^{* * *}$ & $15.040^{* * *}$ & $137.477^{* * *}$ \\
\hline Belgium & 0.308 & 0.495 & -0.714 & 6.451 & $471.820^{* * *}$ & 4.658 & $145.158^{* * *}$ \\
\hline Germany & 0.183 & 0.563 & -0.714 & 5.950 & $363.523^{* * *}$ & $14.624^{* *}$ & $89.920^{* * *}$ \\
\hline Singapore & 0.130 & 0.472 & -0.209 & 7.241 & $614.393^{* * *}$ & $9.487^{*}$ & $119.229^{* * *}$ \\
\hline Korea & 0.205 & 0.705 & -0.570 & 11.166 & $2299.942^{* * *}$ & $20.969^{* * *}$ & $368.039^{* * *}$ \\
\hline Spain & 0.050 & 0.570 & -0.333 & 4.619 & $103.695^{* * *}$ & 5.922 & $128.655^{\text {*** }}$ \\
\hline India & 0.364 & 0.630 & -0.246 & 5.391 & $201.550^{* * *}$ & $12.403^{* *}$ & $75.321^{* * *}$ \\
\hline Japan & -0.057 & 0.461 & -0.238 & 4.638 & $98.443^{* * *}$ & $9.337^{*}$ & $73.354^{* * *}$ \\
\hline French & 0.019 & 0.539 & -0.530 & 5.554 & $258.717^{* * *}$ & $18.177^{* * *}$ & $99.118^{* * *}$ \\
\hline China & 0.306 & 0.573 & -0.576 & 7.512 & $733.778^{* * *}$ & $11.580^{* *}$ & $49.923^{\text {*** }}$ \\
\hline US & 0.099 & 0.387 & -0.617 & 7.847 & $846.404^{* * *}$ & 9.107 & $72.247^{* * *}$ \\
\hline
\end{tabular}

Notes: JB stat, LBQ stat and ARCH stat are the statistics testing for normal distribution, serial correlation and ARCH effect, respectively. **** and ${ }^{* * *}$ denote rejections of null hypothesis at $10 \%, 5 \%$ and $1 \%$ significance levels, respectively. 
Table 3: Estimation results of ADECO.

\begin{tabular}{llrlrr}
\hline & \multicolumn{2}{c}{ Oil-exporting countries } & & \multicolumn{2}{c}{ Oil-importing countries } \\
\cline { 2 - 3 } & params & Standard error & & params & Standard error \\
\hline $\mathrm{a}$ & $0.0096^{* * *}$ & 0.0019 & & $0.0485^{* * *}$ & 0.0059 \\
$\mathrm{~g}($ asym $)$ & $0.0024^{* *}$ & 0.0011 & & $0.0104^{*}$ & 0.0071 \\
$\mathrm{~b}$ & $0.9877^{* * *}$ & 0.0019 & & $0.9207^{* * *}$ & 0.0087 \\
\hline
\end{tabular}

Notes: ${ }^{*},{ }^{* *}$ and ${ }^{* * *}$ denote rejections of null hypothesis at $10 \%, 5 \%$ and $1 \%$ significance levels, respectively.

Table 4: Variance of portfolio.

\begin{tabular}{|c|c|c|c|c|c|c|c|c|}
\hline & \multicolumn{4}{|c|}{ Oil-exporting countries } & \multicolumn{4}{|c|}{ Oil-importing countries } \\
\hline & ADECO & DECO & $\mathrm{ADCC}$ & $\mathrm{DCC}$ & $\mathrm{ADECO}$ & DECO & $\mathrm{ADCC}$ & $\mathrm{DCC}$ \\
\hline \multicolumn{9}{|c|}{ Add energy commodities } \\
\hline Variance & 3.648 & 3.881 & 4.110 & 4.410 & 5.905 & 7.182 & 6.136 & 6.708 \\
\hline $\mathrm{DM}(\mathrm{ADECO}$ vs $)$ & & $-1.396^{*}$ & $-2.172^{* *}$ & $-2.921^{* * *}$ & & $-5.211^{* * *}$ & -0.496 & $-1.582^{*}$ \\
\hline DM(DECO vs ) & & & -0.805 & $-1.609^{*}$ & & & $2.637^{* * *}$ & 1.129 \\
\hline $\mathrm{DM}(\mathrm{ADCC}$ vs $)$ & & & & $-3.058^{* * *}$ & & & & $-5.430^{* * *}$ \\
\hline \multicolumn{9}{|c|}{ Remove energy commodities } \\
\hline Variance & 5.063 & 5.108 & 5.108 & 5.198 & 7.236 & 7.290 & 7.183 & 7.182 \\
\hline $\mathrm{DM}(\mathrm{ADECO}$ vs $)$ & & -1.221 & -0.129 & -0.603 & & -0.770 & 0.433 & 0.303 \\
\hline DM(DECO vs ) & & & 0.064 & -0.416 & & & 0.463 & 0.334 \\
\hline $\mathrm{DM}(\mathrm{ADCC}$ vs $)$ & & & & $-1.419^{*}$ & & & & 0.309 \\
\hline
\end{tabular}

Notes: The variances reported in this table are for the percent returns (i.e., original returns multiplied by 100). The numbers in bold denote that the corresponding model has the lowest variance. $\mathrm{DM}(\mathrm{A}$ and $\mathrm{B})$ means the Diebold and Mariano (1995) statistics testing for the null hypothesis that the predictive accuracy of model A and model B is equivalent.. ${ }^{* * *}$ and ${ }^{* * *}$ denote rejections of null hypothesis at $10 \%, 5 \%$ and $1 \%$ significance levels (one-side test), respectively. 
Table 5: Variance of portfolio when alternative futures contracts are used.

\begin{tabular}{|c|c|c|c|c|c|c|c|c|}
\hline & \multicolumn{4}{|c|}{ Oil-exporting countries } & \multicolumn{4}{|c|}{ Oil-importing countries } \\
\hline & ADECO & DECO & $\mathrm{ADCC}$ & $\mathrm{DCC}$ & $\overline{\mathrm{ADECO}}$ & DECO & $\mathrm{ADCC}$ & DCC \\
\hline \multicolumn{9}{|c|}{ Contract 2} \\
\hline Variance & 3.534 & 3.842 & 4.017 & 4.244 & 5.856 & 7.076 & 6.040 & 6.605 \\
\hline $\mathrm{DM}(\mathrm{ADECO}$ vs $)$ & & $-2.434^{* * *}$ & $-2.366^{* *}$ & $-2.822^{* * *}$ & & $-4.823^{* * *}$ & -0.331 & $-1.429^{*}$ \\
\hline DM(DECO vs ) & & & -0.589 & -1.268 & & & $2.569^{* * *}$ & 1.044 \\
\hline $\mathrm{DM}(\mathrm{ADCC} \mathrm{vs})$ & & & & $-2.541^{* * *}$ & & & & $-5.478^{* * *}$ \\
\hline \multicolumn{9}{|c|}{ Contract 3} \\
\hline Variance & 3.572 & 3.842 & 3.954 & 4.368 & 5.856 & 7.023 & 5.944 & 6.605 \\
\hline DM(ADECO vs ) & & $-3.255^{* * *}$ & $-1.456^{*}$ & $-2.535^{* *}$ & & $-4.589^{* * *}$ & -0.110 & $-1.463^{*}$ \\
\hline DM(DECO vs ) & & & -0.375 & $-1.558^{*}$ & & & $2.610^{* * *}$ & 0.837 \\
\hline $\mathrm{DM}(\mathrm{ADCC} \mathrm{vs})$ & & & & $-3.551^{* * *}$ & & & & $-6.143^{* * *}$ \\
\hline \multicolumn{9}{|c|}{ Contract 4} \\
\hline Variance & 3.648 & 3.842 & 3.985 & 4.537 & 5.808 & 6.970 & 5.923 & 6.605 \\
\hline $\mathrm{DM}(\mathrm{ADECO} \mathrm{vs})$ & & $-2.668^{* * *}$ & $-1.321^{*}$ & $-2.677^{* * *}$ & & $-4.729^{* * *}$ & -0.223 & $-1.558^{*}$ \\
\hline DM(DECO vs ) & & & -0.474 & $-1.896^{* *}$ & & & $2.533^{* * *}$ & 0.782 \\
\hline DM(ADCC vs) & & & & $-3.837^{* * *}$ & & & & $-6.213^{* * *}$ \\
\hline
\end{tabular}

Notes: The variances reported in this table are for the percent returns (i.e., original returns multiplied by 100). The numbers in bold denote that the corresponding model has the lowest variance. $\mathrm{DM}(\mathrm{A}$ and $\mathrm{B})$ means the Diebold and Mariano (1995) statistics testing for the null hypothesis that the predictive accuracy of model $\mathrm{A}$ and model $\mathrm{B}$ is equivalent. ${ }^{*},{ }^{* *}$ and ${ }^{* * *}$ denote rejections of null hypothesis at $10 \%, 5 \%$ and $1 \%$ significance levels (one-side test), respectively. 

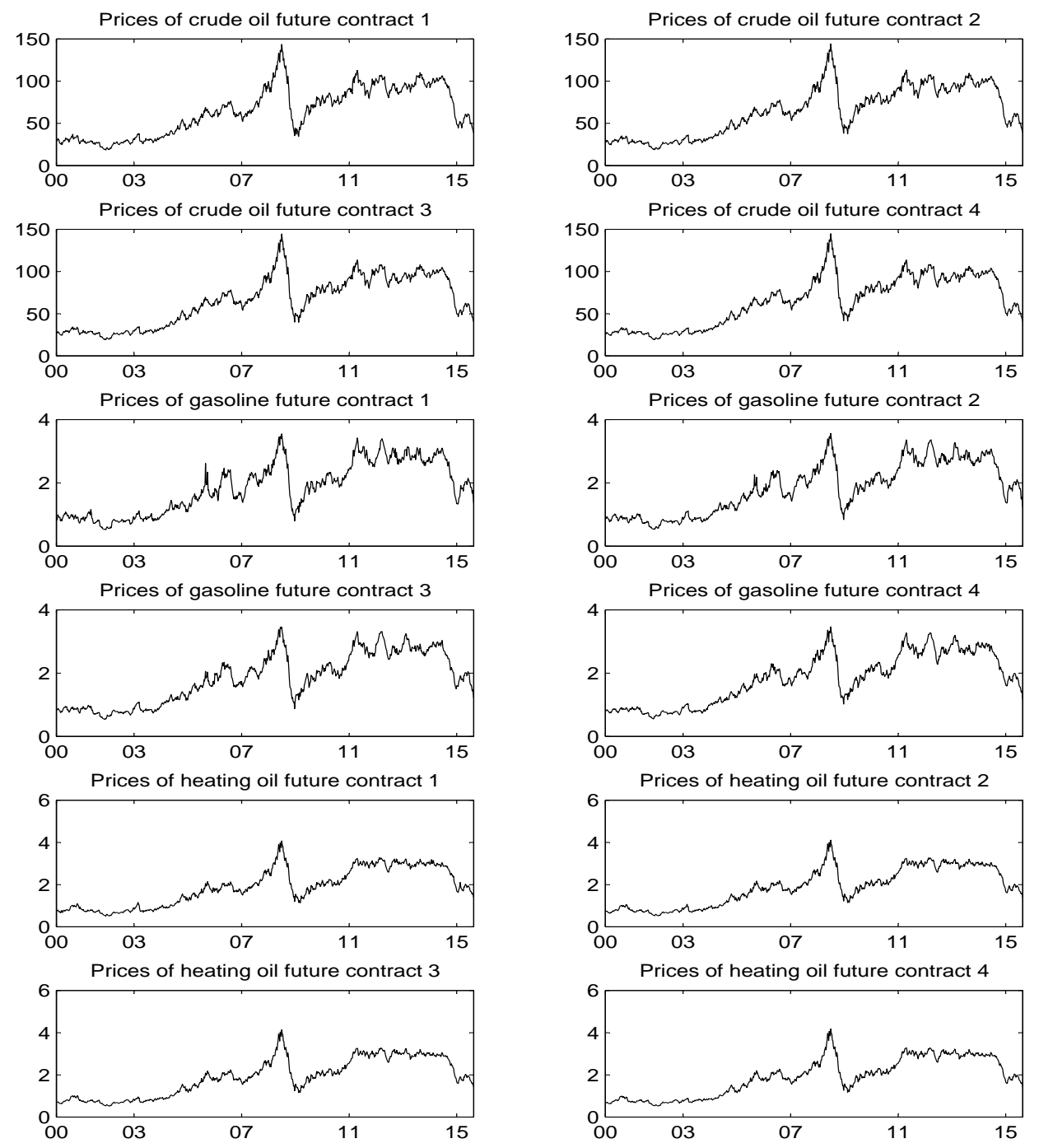

Figure 1: Energy futures prices with different maturities 

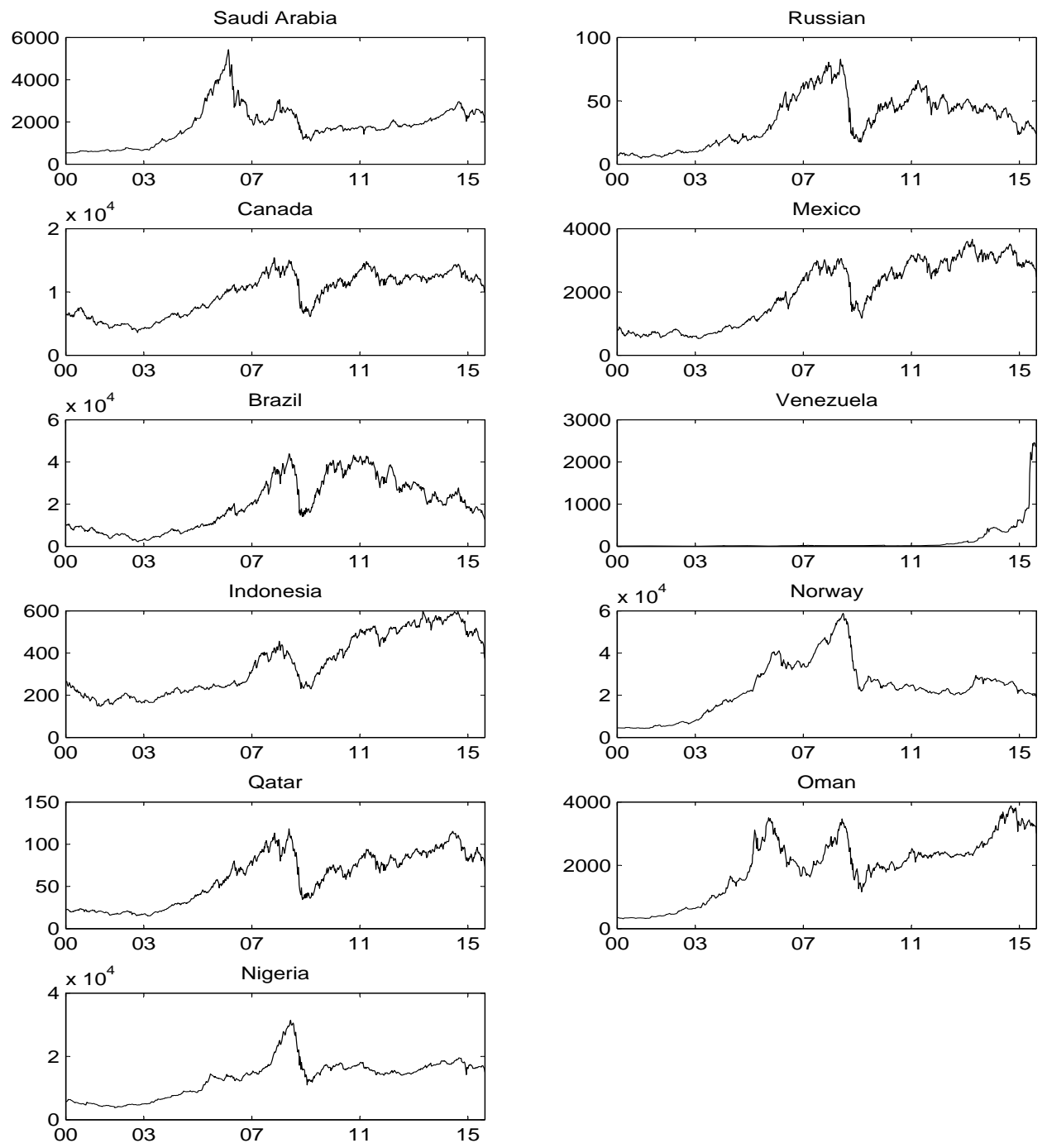

Figure 2: Stock indices in oil-exporting countries 

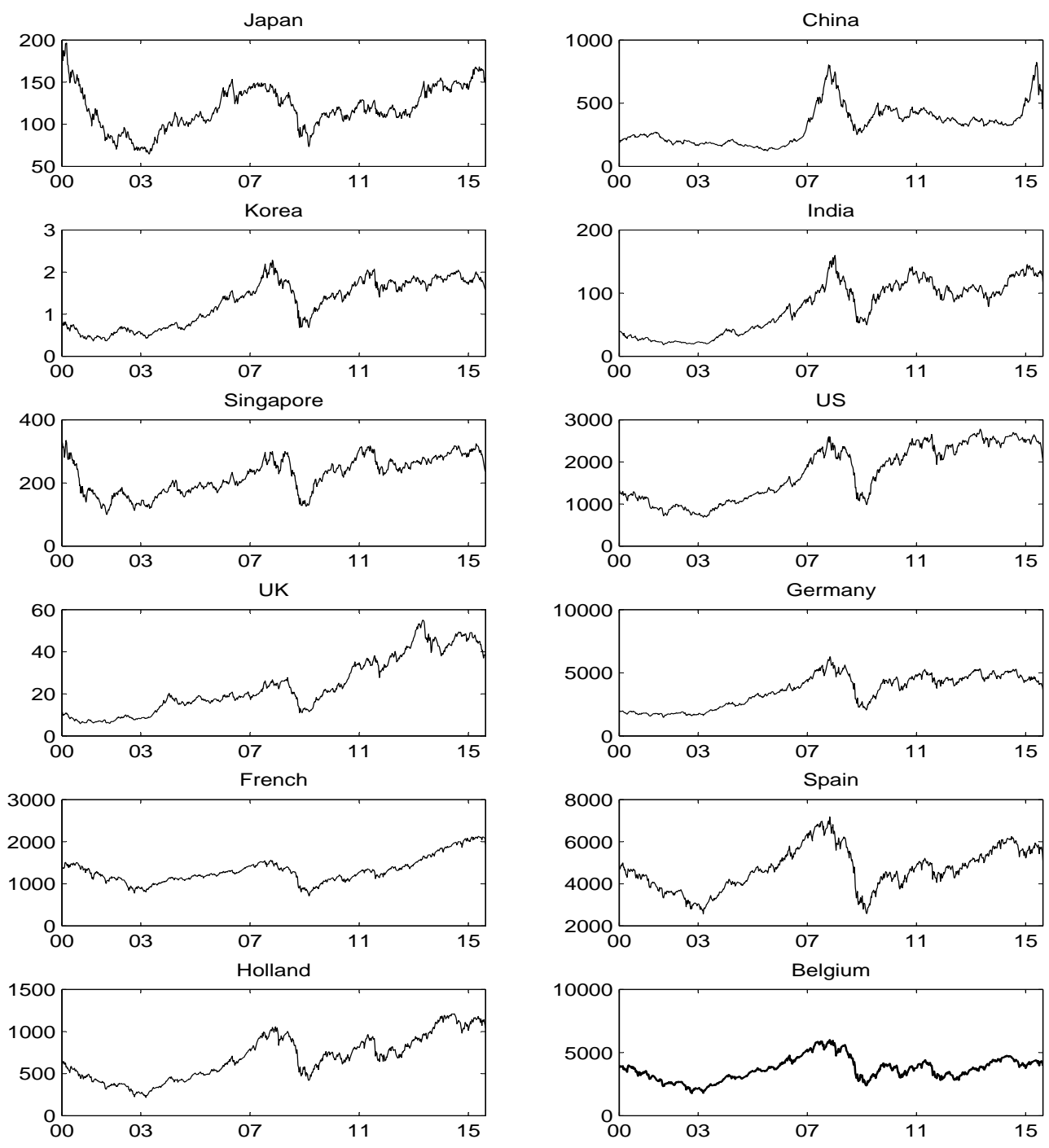

Figure 3: Stock indices in oil-importing countries 


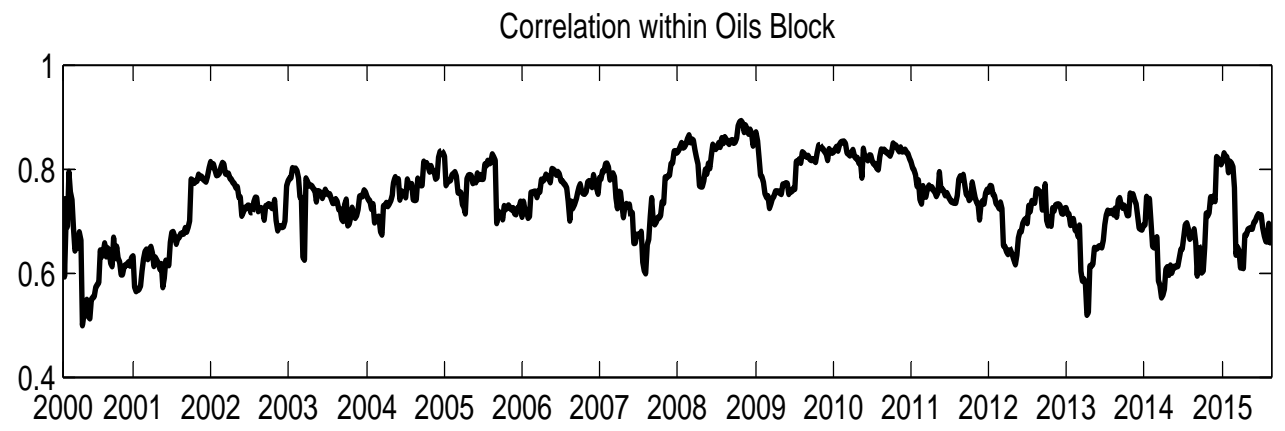

Correlation within Stocks Block

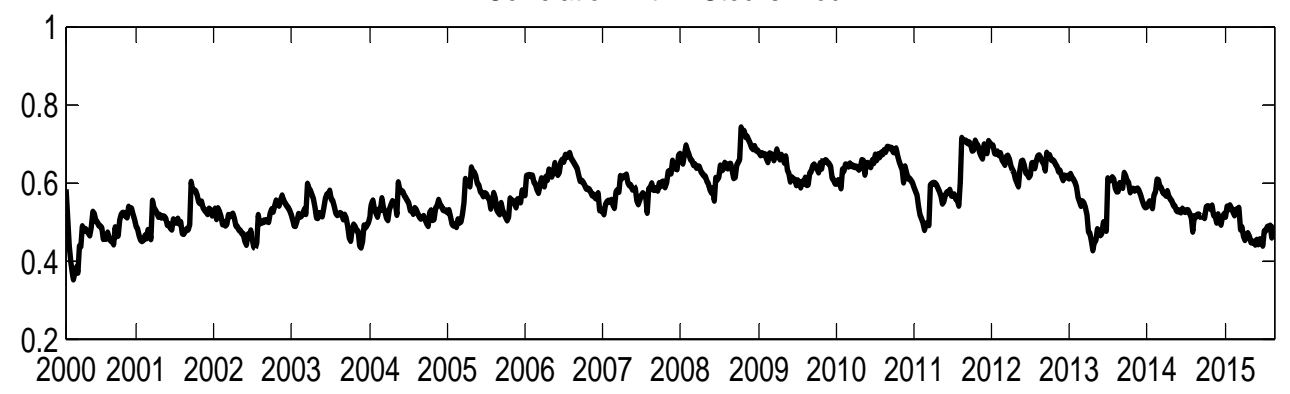

Correlation between Oils and Stocks

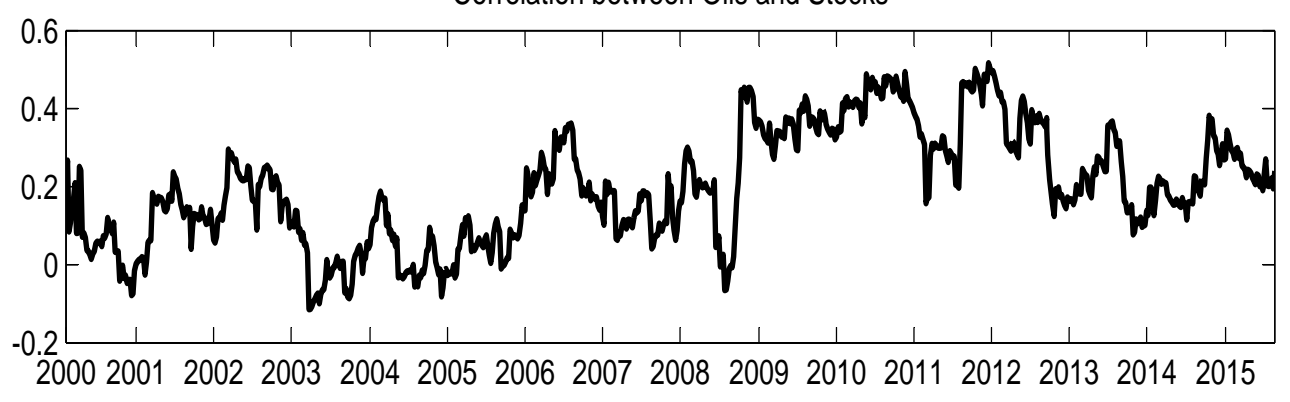

Figure 4: Equi-correlations for returns of energy futures and stock indices in oil-importing countries 

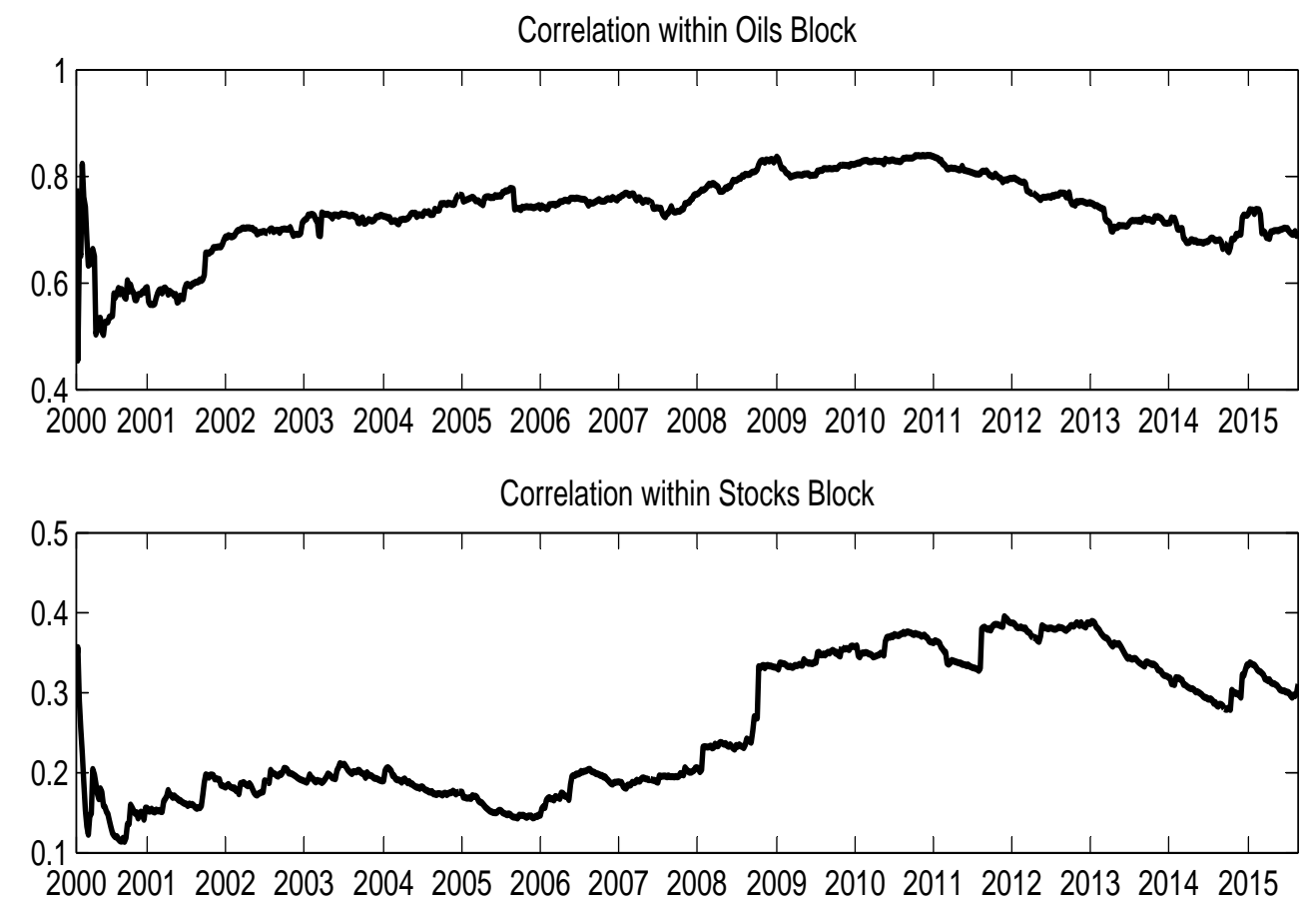

Correlation between Oils and Stocks

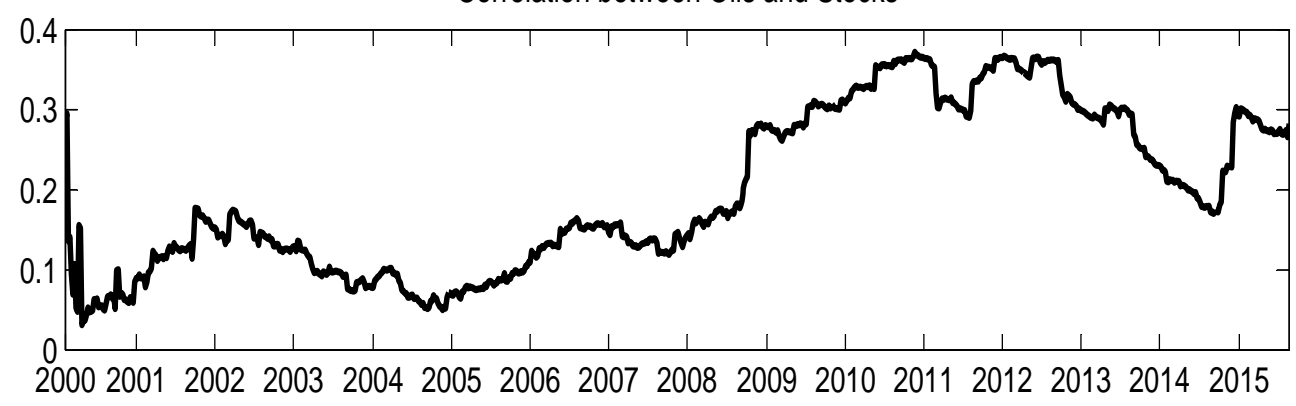

Figure 5: Equi-correlations for returns of energy futures and stock indices in oil-exporting countries 